\title{
Short-term effects of combined training on the performance of the Brazilian women's basketball team
}

\section{Efeitos de curto prazo do treinamento combinado da seleção brasileira de basquetebol feminino}

\author{
João Paulo Borin ${ }^{1}$ \\ (D) https://orcid.org/0000-0002-7393-4053 \\ Clovis Roberto Rossi Haddad \\ (D) https://orcid.org/0000-0001-5236-383X \\ José Francisco Daniel ${ }^{2}$ \\ (i) httos://orcid.org/0000-0001-8148-581X \\ Andressa Mella Pinheiro \\ (iD) httos://orcid.org/0000-0003-4533-9123 \\ Leandro de Melo Beneli ${ }^{3}$ \\ (i) https://orcid.org/0000-0002-8669-9902 \\ Rafael J.F.G. Fachina \\ (D) https://orcid.org/0000-0002-4134-6134 \\ Paulo Cesar Montagner \\ (D) https://orcid.org/0000-0002-5764-8022
}

Abstract - Competitions are considered of paramount importance for high-performance sports because they determine the entire orientation of the training process. When analyzing the calendar of the International Basketball Federation, it can be observed that international competitions occur in short periods of time. In this sense, the aim of this study was to verify the effects of the application of combined training in the short-term preparation period on the speed of athletes of the Brazilian women's basketball team. Thirteen athletes participated in this study, who took part of the preparation for the 2015 Pan American Games. Athletes were submitted to anthropometric measures and biomotor capacity evaluation at cyclic speed - 20m run, and acyclic speed - T test at the beginning (M0) and end of a 27 - day preparation period (M1). Considering the period available for training, the total duration percentage was: technical / tactical $73.7 \%$, strength and conditioning: $5.7 \%$, preventive: $10.5 \%$ and general and special warm up: $10.1 \%$. After data collection, the Shapiro-Wilk test was used to verify normality and then, the Student's T test was also applied. The main results indicate that the best time to evaluate cyclic speed ( $\mathrm{M} 0$ and $\mathrm{M} 1$, respectively) was $3.34 \pm 0.22 \mathrm{~s}$ and $3.39 \pm 0.21 \mathrm{~s}$ and acyclic speed (M0 and M1, respectively), $9.30 \pm 0.49 \mathrm{~s}$ and $9.52 \pm 0.57 \mathrm{~s}$. The results of the current study suggest that short-term intervention was not efficient to improve the cyclic and acyclic speed of female basketball athletes.

Key words: Athletic Performance, Sports, Exercise

Resumo - As competições são consideradas o elemento central para o desporto de rendimento, pois determinam toda a orientação do processo de treinamento. Ao observar o calendário da Federação Internacional de Basquetebol, percebe-se que as competiçōes internacionais acontecem em curtos periodos de tempo. Neste sentido, o objetivo deste trabalho foi verificar os efeitos da aplicação do treinamento combinado na preparação de curto prazo, sobre a capacidade biomotora velocidade, em atletas adultas da seleção brasileira de basquetebol feminino. Participaram deste estudo 13 atletas da seleção brasileira de basquetebol feminino da categoria adulta, que fizeram parte da preparação para a disputa dos Jogos Pan Americanos em 2015. As atletas foram submetidas a medidas antropométricas e avaliação da capacidade biomotora velocidade ciclica - corrida de $20 \mathrm{~m}$, e acíclica - teste T, no início (MO) e ao final de um período de preparação de 27 dias (M1). Considerando o periodo disponivel para treinamento ० \% da duração total foi de: técnico/tático 73,7\%, físico: 5,7\%, preventivo: $10,5 \%$ e aquecimento geral e especial: 10,1\%. Após a coleta dos dados utilizou-se o teste de Shapiro-Wilk para verificar a normalidade e, a seguir, o teste $T$ de Student. Os principais resultados apontam que o melhor tempo

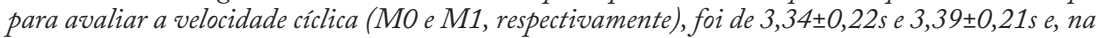

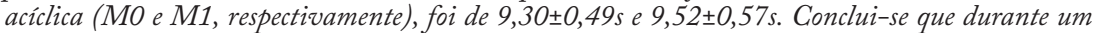
curto periodo de intervenção, com grande concentração de estimulos, não foi eficiente para melhorar a capacidade biomotora velocidade cíclica e acíclica.

Palavras-chave: Desempenho Atlético, Esportes, Exercício
1 State University of Campinas. School of Physical Education. Campinas, SP. Brazil.

2 Catholic University of Campinas. Campinas, SP. Brazil.

3 University of São Paulo. Campinas, SP. Brazil.

Received: 20 0ctober 2018 Accepted: 30 May 2019

How to cite this article Borin JP, Haddad CRS, Daniel JF, Pinheiro AM, Beneli LM, Fachina RJ, Montagner PC. Short-term effects of combined training on the performance of the Brazilian female basketball team. Rev Bras Cineantropom Desempenho Hum 2019, 21:e59839. D0l: http://dx.doi. org/10.1590/1980-0037.2019v21e59839

Copyright: This work is licensed under a Creative Commons Attribution 4.0 International License. 


\section{INTRODUCTION}

Basketball is considered one of the most popular sport modalities in the world. Thus, the scientific community has shown great interest in conducting studies, including those related to performance factors and physiological load related to this sport modality ${ }^{1}$.

Over the past few years, many authors have studied basketball with the aim of evaluating the aspects that characterize it as a game ${ }^{2}$, identifying the physiological profile of athletes ${ }^{3}$, analyzing responses from different training models ${ }^{4-7}$, and comparing training methods ${ }^{8}$. Such surveys have contributed throughout the years to the characterization of the modality and offered support for the improvement of the training process. It was observed that studies in which findings are contextualized with the other components of the training process present results that come from a long preparation period ${ }^{4,6}$.

The competitive demand of most modalities has increased considerably over the past decades. If in previous years, athletes had a long preparation time to reach their best performance condition during the main competition, today, the number of competitions and their density have increased throughout the training macrostructure, requiring new adjustments to existing training periodization models?.

In this context, when observing the calendar of the International Basketball Federation (FIBA), it can be observed that international competitions in the modality occur in short periods of time. In a few days, athletes are submitted to a large number of games and mostly on consecutive days. The number of national competitions have also increased, which makes the time available for training aimed at the preparation of athletes for competitive demands increasingly restricted.

Given this scenario, characterized by limited training time and considering international competitions with increasingly demanding technical and physical requirements, there are few studies that point to the integration of means and methods of preparation, as well as to monitor the performance of athletes to achieve higher performance levels.

In this sense, the aim of this study was to verify the effects of the application of combined training in the short-term preparation on the biomotor capacity speed (cyclic and acyclic) of adult athletes of the Brazilian women's basketball team.

\section{METHOD}

Thirteen athletes from the Brazilian women's basketball team aged 25.3 \pm 4.9 years and height of $178.0 \pm 8.0 \mathrm{~cm}$, participated in this study, who participated of the preparatory period for the 2015 Pan Games Americans.

To participate in this study, athletes were informed about all procedures and accepted all conditions, signing the informed consent form. The work was approved by the Research Ethics Committee of UNICAMP under protocol number 1.375.752, CAAE 50873515.5.0000.5404. 
Training sessions occurred during 23 days distributed in three microcycles. The training components during the total period were distributed as follows: technical / tactical 73.7\%, physical: 5.7\%, preventive: 10.5\% and general and special warm-up: 10.1\%.

Box 1 presents the classic training components: physical, technical and tactical and their respective session contents based on the main objective and its use.

Box 1. Content of training sessions and activity description

\begin{tabular}{ll}
\hline Content of training sessions & Activity description \\
\hline Preventive Training (PT) & $\begin{array}{l}\text { Sensory motor activation exercises, static and dynamic } \\
\text { balance exercises, eccentric training. } \\
\text { Displacements at low intensity with amplitude of move- } \\
\text { ments, diversified stimuli of locomotion and motor } \\
\text { coordination skills. }\end{array}$ \\
Use of the continuous variable method through cyclic \\
and acyclic exercises with and without displacements \\
performed with variations of speed, changes of directions \\
and jumps.
\end{tabular}

Training load control was performed using the session PSE method proposed by Foster et al. ${ }^{10}$. This method consists in recording the total period in minutes of a training session and multiplying it by the average PSE reported by athletes 30 minutes after the end of the session, when athletes were asked to indicate the corresponding number on the CR-10 scale ${ }^{11}$.

PSE was individually collected and without the proximity of another subject of the team to avoid any form of interference in their response. The information was obtained by pointing at the scale (without pronouncing the value verbally). In this investigation, training components were applied in the same environment and the transition from one to another occurred sequentially with minimum time interval. Thus, it was established that the time of all actions programmed for a training session would be summed and computed as the total time for the load calculation. The result of multiplying the total time of the training session by the average PSE of the team was considered the internal load of the training session, presented in arbitrary units (AU).

The daily internal training load was obtained by the sum of loads measured in each session performed on the day. From the daily internal training load values, three indexes are also obtained: weekly training load, monotony and strain. The weekly training load was calculated by summing all the daily values; monotony by dividing the value found in the average weekly training load by the standard deviation of the average and, finally, strain, calculated by multiplying the monotony value by the weekly training load. 
To evaluate the displacement speed in 20 meters, the time for athletes to complete the trajectories was initially measured, as suggested by Eston and Reilly ${ }^{12}$. For this, two pairs of photocells (CEFISE, Speed Test Fit ${ }^{\circledR}$ ) were used at the starting point $(0 \mathrm{~m})$ and final point $(20 \mathrm{~m})$. Athletes were instructed to stand with one foot at the starting point and run as fast as possible to the end of the course. After passing the endpoint, the evaluator informed the time in seconds to the recorder. Each athlete made two attempts with interval ranging from three to five minutes. The best result of both trials at each moment was used. Then, to calculate the speed, the distance of 20 meters was divided by the time elapsed.

In the acyclic speed, the protocol proposed by Pauole et al. ${ }^{13}$ was followed, in which athlete standing behind the start-finish line, at command go, traveled a distance of 10 meters straight to a line marked with a cone; stepped on this line and changed direction to the left without crossing his legs (sudden stop, followed by a change of direction); they ran a distance of five meters to another line also demarcated with a cone; when the athlete stepped on that line, she returned in the previous direction, but went to the other end of the $\mathrm{T}$, then ran another 10 meters (five meters to the center cone, another five meters to the left cone); when she stepped on the line (left), the athlete returned to the center cone, ran a distance of five meters, and then went to the start-finish line, totaling 40 meters. For this, two pairs of photocells (CEFISE, Speed Test Fit ${ }^{\circledR}$ ) were used. The best result of the two attempts at each moment was used.

\section{Statistical analysis}

For the analysis of collected data, descriptive statistics were used through the mean and standard deviation and to verify the normality, the ShapiroWilk test was used. The speed test results were analyzed by the paired T-test. The effect size was calculated using Cohen's " $d$ ". To analyze the magnitude of the effect size for trained individuals, the $\mathrm{Rhea}^{15}$ classification was used: trivial $<0.25,0.25<$ small $<0.50,0.50<$ moderate $<1.0$, large $>1.0$. The significance level was set at 0.05 . All analyses were performed in the GraphpadPrism 6.0 software.

\section{RESULTS}

The results found in the present study show that the preparatory period included a volume of 67 hours of training distributed in the different training components by time and percentage of the total time used (Table 1). It could be immediately verified that most of the training was aimed at the technical and tactical components of the modality.

Regarding internal load control, Figure 1 and Table 2 show the weekly training load distribution on the three training microcycles. Data of total daily internal load and weekly load indexes are presented.

In the first training microcycle, the daily internal load values oscillated, presenting a slight downward trajectory. Monotony and strain levels were high. 
In the second training microcycle, two blocks of three days are presented, with high starting loads, which decreased on the subsequent two days. The session PSE values were more distinct, the same was observed for the daily internal load, explaining training differences, consequently a decrease in monotony and strain can be observed.

In the third training microcycle, both session PSE and daily internal load data remained distinct. The decrease in the total week value shows the decrease in strain, despite an increase in monotony.

Table 3 presents the time results in speed tests at the evaluated moment. It was verified that the results in both speed capacities (cyclic and acyclic) showed a decrease after the training session.

Table 1. Distribution of the training volume in the different training components in hours and time percentage (\%)

\begin{tabular}{lcc}
\hline Training components & Total Duration (h) & Total Duration (\%) \\
\hline Preventive & $7: 01$ & $10.5 \%$ \\
General Warm-up & $3: 23$ & $5.0 \%$ \\
Special Warm-up & $3: 25$ & $5.1 \%$ \\
Mixed IT (IT-Mi) & $1: 45$ & $2.6 \%$ \\
TI Anaerobic Lactic (IT-AL) & $2: 04$ & $3.1 \%$ \\
Technical / Tactical & $49: 22$ & $73.7 \%$ \\
\hline
\end{tabular}
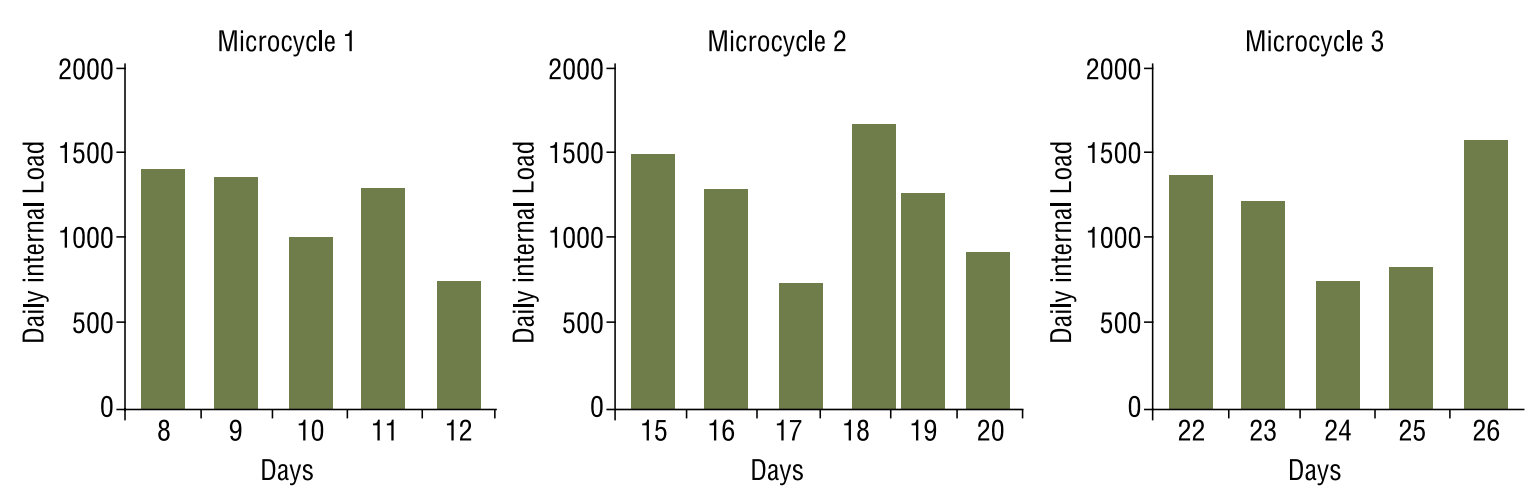

Figure 1. Total daily internal load of the three training microcycles.

Table 2. Weekly load indexes over three training microcycles.

\begin{tabular}{|c|c|c|c|c|c|}
\hline & $\begin{array}{l}\text { Total weekly load } \\
(A U)\end{array}$ & $\begin{array}{l}\text { Average weekly load } \\
(\mathrm{AU})\end{array}$ & Standard Deviation & Monotony & Strain \\
\hline Microcycle 1 & 6.004 & 1.001 & 226.8 & 4.41 & 26.488 \\
\hline Microcycle 2 & 6.564 & 1.094 & 382.2 & 2.86 & 18.786 \\
\hline Microcycle 3 & 5.314 & 1.063 & 351.8 & 3.02 & 16.053 \\
\hline
\end{tabular}

Note. $\mathrm{AU}=$ Arbitrary Units

Table 3. Descriptive measures and result of the $p$ value of speed tests at the evaluated moment.

\begin{tabular}{lllllll}
\hline Capacity & Evaluated Variable & Evaluated Moment & & $\Delta \%$ & P Value & Effect size \\
\hline Biomotor & & M0 & M1 & & & \\
Cyclic speed & Best time (s) & $3.34 \pm 0.22$ & $3.39 \pm 0.21$ & 1.49 & $0.01^{*}$ & 0.23 \\
Acyclic speed & Best time (s) & $9.30 \pm 0.49$ & $9.52 \pm 0.57$ & 2.36 & $0.01^{*}$ & 0.41 \\
\hline
\end{tabular}

Note. * Significant difference in relation to M0, $p<0.05$ 


\section{DISCUSSION}

From the proposed objectives to verify the effects of a short-term training model on the speed capacity, the results show that the proposed training using two interval training variations distributed in a short period of time for cyclic and acyclic speed showed significant worsening.

In the last decade, researchers in the field of exercise physiology ${ }^{16}$ have made great efforts to raise more evidences regarding the effects of interval training (IT), mainly in its variation characterized by high intensities.

Although short sprints represent a small portion of the total time of a match in collective games, the importance of these sprints is considered critical to the match outcome ${ }^{17}$.

Buchheit et al. ${ }^{18}$ investigated two different approaches to the discontinuous interval method in young handball players ( $15.8 \pm 0.9$ years), cited as having good training level in the modality. The experiment lasted four weeks, with two training sessions per week. Athletes were divided into two groups: G1 and G2. G1 athletes performed three to four sets of four replicates. Each replicate involved acceleration and change of direction exercises, with maximum duration of five seconds. The micro pause (between repetitions) was 30 seconds and the macro pause (between sets) was three minutes. However, G2 participants performed three to five sets of one replicate consisting of acceleration and change of direction exercises, but with fixed duration of 30 seconds. The interval between each series was two minutes. At the end of the experiment, no significant change was found in the time to run $10 \mathrm{~m}$ at $\mathrm{Tm}$, Tmed and in the FI of the anaerobic resistance test in both groups. Buchheit et al. ${ }^{18}$ found no significant differences regarding the maximum time in the $20 \mathrm{~m}$ run test. Conversely, in the present study, Tm presented worsening in the $20 \mathrm{~m}$ test.

In another study with Lithuanian basketball players aged 15-16 years, Balciunas et al. ${ }^{6}$ investigated how two different training models could influence speed, lower limb power and anaerobic endurance of athletes. These athletes had already completed a four-week pre-season (not detailed in the study) and the investigation began during the first 16 weeks of the competitive period (Lithuanian championship). Athletes were divided into three groups: PE (Power Endurance), GE (General Endurance) and CG (Control Group). Training sessions lasted 90 minutes and were held three times a week.

The PE group used HR monitors in their training sessions, with the target area stipulated between 78 and $83 \%$ of maximum HR. They performed periods of 15 minutes of activity with stimuli of 50 seconds and passive recovery intervals of 20 seconds. Each period focused on one of the following basketball fundamentals: passing, carrying and shooting. The last 15 minutes were aimed at tactical work using five against five $(5 \times 5)$ entire court. The periods had a two-minute break between them and a longer break (15 minutes) in the middle of the session for the coach to give directions and corrections. The authors classified the activity of this group as specific high-intensity intermittent exercises. 
The GE group used six 10-minute periods, with 10 free throws for each player in the interval between them. The stimuli were of 15 seconds, with equal recovery value and the focus was what the authors called active defense, using exercises as one against one (1x1); two against two $(2 \times 2)$ and three against three $(3 \times 3)$. The remaining 30 minutes were directed to tactical work using five against five $(5 \times 5)$ entire court. Intensity had no specific control.

Finally, CG performed only what the authors called standard Lithuanian training: 20 minutes of warm-up, 40 minutes for individual technical aspects and 30 minutes for tactical aspects, also without intensity control.

At the end of 16 weeks, none of the groups studied by Balciunas et al. ${ }^{6}$ presented statistically significant difference for the time spent to cover the 20-m distance, nor for the values found for vertical jumps.

Regarding the control of internal training load, the findings of Foster et al. ${ }^{19}$ show that the session PSE method was presented as a reliable subjective measure to estimate the training load during exercises where a physiological stable state is not reached, such as training and competition in collective sports. Thus, the method can combine, in a single number, the combined actions of variables effort intensity and duration.

Manzi et al. ${ }^{20}$ found value of 3,334 AU for the total weekly load for the week in which there was no game, 2,928 AU for the week with one game and 2,791 AU for the week with two games. The study was carried out with professional players of an Italian men's basketball team, who played the Euroleague (one of the main European championships).

When analyzing the total weekly load used in the present study (Table 2 ), it was observed that the values found for women were much higher in all three weeks (6,004, 6,564 and 5,314 AU for weeks one, two and three, respectively), which at first may seem exaggerated values. It is important to emphasize that this is the first study evaluating an adult national team preparing for an international competition where they would play five consecutive matches with few hours of recovery between games and with a training period of only 27 days.

Thus, the values presented can serve as a reference for daily internal loads in the training of female basketball athletes of international level.

Analyzing data (Figure 1 and Table 2), it is observed that the peak volume fell over week two, when the total training volume was 6,564 AU. However, the monotony value of this week (2.86) was the lowest. This indicates that the training sessions were quite different with respect to the volume / intensity relationship. Since no athlete was absent from any of the team's activities (there was no withdrawal due to injury or any other physical / clinical reasons), the high internal training load values alone do not seem to cause harm to athletes' health, considering that the training period was only a few days. However, it is necessary to consider that these results were obtained with adult athletes of international level and concentration environment, where rest and feeding, as well as training, were highly controlled. 


\section{CONCLUSIONS}

The findings of this study demonstrated that the use of the discontinuous interval training method during a short intervention period with high concentration of stimuli demonstrated a decrease in the cyclic and acyclic speed biomotor capacities.

In reference to the distribution of the training volume within contents, the predominance of technical and tactical components in relation to the total training volume within the macrocycle was demonstrated. This seems to indicate that punctual and controlled interventions in the physical component of training could make a significant difference in the final training outcome.

It is noteworthy that the PSE-s method proved to be very efficient and reliable for the control of internal training loads, since it objectively presented the load variability for each training microcycle. Thus, the use of this method is an important tool for the control of loads in female adult basketball players.

Finally, taking into consideration the challenges that the training of a high-performance basketball team presents, with emphasis on the verified model, it becomes feasible that, in addition to the concentrated application of IT stimuli and control by PSE-s, both strength training and final preparation with stimuli more focused on the improvement of cyclic and acyclic speed can be added to the training planning. Nevertheless, it is very important that coaches carry out intense application of the technical and tactical works in a way closer to the demand of competitions so that the transfer and assimilation of all stimuli are effective.

\section{COMPLIANCE WITH ETHICAL STANDARDS}

\section{Funding}

This study was financed in part by the Coordination for the Improvement of Higher Education Personnel - Brazil (CAPES) - Finance Code 001.

\section{Ethical approval}

This study was approved by the Research Ethics Committee of the University of Campinas (CAAE: 50873515.5.0000.5404.).This research is in accordance with the standards set by the Declaration of Helsinki.

\section{Conflict of interest statement}

The authors have no conflict of interests to declare.

\section{Author Contributions}

Conceived and designed the experiments: JPB, PCM, CRRH, RJFGF. Performed the experiments: CRRH, RJFGF. Analyzed data: JPB, PCM, CRRH, RJFGF, JFD. Contributed with reagents/materials/analysis tools: AMP, LMB, JFD. Wrote the paper: JPB, PCM, CRRH, RJFGF. 


\section{REFERENCES}

1. Silva LO, Campo SS. Características del esfuerzo em competición em jugadoras de baloncesto de elite durante las fases finales de la Euroliga y el Campeonato del Mundo. Rev Int Cienc Deporte 2013, 34 (9): 360-376.

2. Zwierko T, Lesiakowski P. Selected parameters of speed performance of basketball players with different sport experience levels. Stud Phys Culture Tour 2007; 14: 307-312.

3. Ostojic SM, Mazic S. Profiling in basketball: Physical and physiological characteristics of elite players. J Strength Cond Res 2006; 20(4):740-744.

4. Moreira A, Oliveira PR. A dinâmica de alteração das medidas de força e o efeito posterior duradouro de treinamento em basquetebolistas submetidos ao sistema de treinamento em bloco. Rev Bras Med Esporte 2004; 10(4):243-250.

5. Moreira A, Okano AH. Sistema de cargas seletivas no basquetebol durante um mesociclo de preparação: implicações sobre a velocidade e as diferentes manifestações da força. Rev Bras Ciênc Mov 2005;13(3):7-16.

6. Balciunas M, Stonkus S. Long term effects of different training modalities on power, speed, skill and anaerobic capacity in young male basketball players. J Sports Sci Med 2006;5:163-170.

7. Beneli LM, Rodrigues EF. Periodização do treinamento desportivo para atletas da categoria infantil masculino de basquetebol. Rev Treinam Desportivo 2006;7(1): 29-35.

8. Bogdanis GC, Ziagos V. Effects of two different short-term training programs on the physical and technical abilities of adolescent basketball players. J Sci Med Sport 2007;10(2):79-88.

9. Forteza A. Entrenamiento desportivo: ciência e innovación tecnológica. La Habana: Científico-Técnica; 2001.

10. Foster C. Monitoring training in athletes with reference to overtraining syndrome. Med Sci Sports Exercise 1998; 30(7):1164-1168.

11. Borg G. Psychophysical bases of perceived exertion. Med Sci Sports Exec 1982;14(5):377-381.

12. Eston R, Reilly T. Kinanthropometry and exercise physiology laboratory manual: tests, procedures, and data. Oxon: Routledge, 2009.

13. Pauole K, Madole K. Reliability e validity of the T-Test as a measure of agility, leg power and leg speed in college-age men and women. J Strength Cond Res 2000; 14(4):443-450.

14. Cohen J. Statistical power analysis for the behavioral sciences. Hillsdale, New Jersey: Erlbaum, 1988.

15. Rhea MR. Determining the magnitude of treatment effects in strength training research through the use of the effect size statistic. J Strength Cond Res 2004;18(4):918-920.

16. Buchheit M, Laursen PB. High-intensity interval training,solutions to the programming puzzle. Part I: cardiopulmonar emphasys. Sports Med 2013; 43(5):313-338.

17. Reilly T, Bangsbo J. Anthropometric and physiological predispositions for elite soccer. J Sports Sci 2000;18(9):669-683.

18. Buchheit M, Mendez-Villanueva A. Improving acceleration and repeated sprint ability in well-trained adolescent handball players: speed versus sprint interval training. Int J Sports Phys Performance 2010;5(2):152-164.

19. Foster C, Florhaug JA, Franklin J, Gottschall L, Hrovatin LA, Parker S, et al. A new approach to monitoring exercise training. J Strength Cond Res 2001; 15(1):109-115.

20. Manzi V, D'ottavio S. Profile of weekly training load in elite male professional basketball players. J Strength Cond Res 2010;24(5):1399-1406.

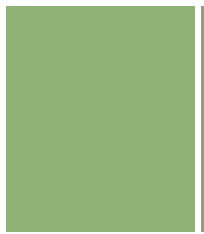

Corresponding author

João Paulo Borin

University of Campinas - Physical Education College -

Av Érico Veríssimo, 701. University City "Zeferino Vaz"

Barão Geraldo - Campinas - SP, Brazil

Zip code: 13083-851

E-mail: borinjp@fef.unicamp.br 